\title{
RESULTS OF A VACCINATION CAMPAIGN AGAINST HUMAN PAPILlOMAVIRUS IN THE PROVINCE OF LA SPEZIA, LIGURIA, ITALY, MARCh-DECEMBER 2008
}

J Lugarini (jessica.lugarini@unige.it) ${ }^{1}$, F Maddalo²

1. Department of Health Sciences, University of Genoa, Italy

2. Operative Unit of Hygiene and Public Health, Local Health Service (Azienda Sanitaria Locale, ASL) 5 “Spezzino”, La Spezia, Italy

This article was published on 1 October 2009

Citation style for this article: Lugarini J, Maddalo F. Results of a vaccination campaign against human papillomavirus in the province of La Spezia, Liguria, Italy, MarchDecember 2008. Euro Surveill. 2009;14(39):pii=19342. Available online: http://www.eurosurveillance.org/ViewArticle.aspx?ArticleId=19342

Sexually transmitted diseases caused by human papillomavirus (HPV) are being diagnosed more frequently than others. It is accepted that HPV infection is a necessary cause for all cases of cervical carcinoma and a large number of other anogenital and oral cancers. Two vaccines have been developed and were licensed in 2007, which can prevent infections and pre-cancerous lesions due to HPV. In Italy pre-adolescent age (12 years-old) was identified as the ideal age for vaccination against HPV. In Liguria, the first free HPV vaccination campaign was started on 8 March 2008 in 12 year-old girls. We assessed the adherence to the vaccination during the 2008 campaign as $80.6 \%, 79.0 \%$ and $64.1 \%$, respectively, for the first, second and third dose of vaccine in the target population.

\section{Introduction}

Sexually transmitted diseases caused by human papillomavirus (HPV) are being diagnosed more frequently than others. Today it is universally accepted that HPV infection is the necessary, although not sufficient, cause of all cases of cervical carcinoma and of a large number of other anogenital cancers and oral squamous cell carcinoma [1].

Certain viral genotypes, defined as high-risk (HR) carcinogenic genotypes (e.g. HPV types 16, 18, 31, 33, 35, 45, 52, 58) are associated more strongly with the development of tumours than others [4], and among these, genotypes 16 and 18 are most relevant in the context of cervical carcinogenesis [5-8]. The lowrisk viral genotypes, including HPV6, 11, 40, 42, 43, 44, 54, 61, $70,72,81$, cause benign laesions such as anogenital condyloma and laryngeal papilloma [9].

Cervical cancer affects approximately 1.4 million women in the world, with an annual incidence of 500,000 cases [2] and causes an estimated 274,000 deaths each year. In Europe, cervical cancer affects approximately 60,000 women and 30,000 die because of this disease every year [3]. In Italy, recent numbers indicate that an estimated 3,500 women are diagnosed with cervical cancer every year and approximately 1,200 die. Cervical cancer occupies the tenth position for cancers affecting women in Italy and is the third most common cancer in women between the ages of 15 and 44 years. It is estimated that about $10.3 \%$ of women in Italy have an HPV infection and that $71.7 \%$ of invasive cervical cancers are attributable to the high-risk HPV genotypes 16 and 18 [3].

\section{Vaccines}

Two vaccines have been developed, Cervarix and Gardasil, that can prevent infections and pre-cancerous laesions caused by HPV infection. They consist of recombinant viral capsid protein L1 (or a combination of L1 and L2) of HPV genotypes 6, 11, 16 and 18 , assembled into virus-like particles (VLPs), and induce the production of neutralising antibodies against these genotypes. Since these vaccines do not contain HPV DNA they cannot cause infection or have an oncogenic effect by integrating into the DNA of the host cell [10-12]. Cervarix is a bivalent vaccine developed by GlaxoSmithKline, containing VLPs of the L1 proteins of HPV16 and $18,20 \mu \mathrm{g}$ of each, with an adjuvant of aluminium salts and a lipid agent (ASO4). The vaccination protocol foresees three intramuscular doses of $0.5 \mathrm{ml}$ (at 0,1 and 6 months) for girls from 10 to 25 years of age. The quadrivalent vaccine Gardasil was developed by Sanofi Pasteur MSD. The vaccine contains $20 \mu \mathrm{g} L 1$ VLPs of HPV 6 and 18 and $40 \mu \mathrm{g}$ L1 VLPs of HPV 11 and 16 . The purified particles were adsorbed with aluminium salts that act as adjuvant. The protocol for the vaccine foresees three intramuscular doses of $0.5 \mathrm{ml}$ (at 0,2 and 6 months) for girls from nine to 26 years of age $[13,14]$.

Both vaccines are considered to be safe and several studies document seroconversion to all types of HPV contained in the vaccine in more than $98 \%$ of cases. The antibody peak occurs a month after the third dose, then it decreases slowly until 18 months. In general, the antibody titres decrease 10-fold in the first one or two years post vaccination and stabilise after three to five years at levels higher than those induced by the natural infection. The quadrivalent vaccine showed $100 \%$ and $99 \%$ efficacy, respectively, against cervical intraepithelial neoplasia grade $2 / 3$ and condyloma. The bivalent vaccine proved $100 \%$ effective in the prevention of cervical dysplasia [15-18]. At this point in time, it is not known how long the protection by the HPV vaccine lasts and whether a later booster vaccination will be necessary. However, preliminary results have shown that a booster with monovalent HPV16 vaccine induced a quick, very high and prolonged immune response [19].

The bivalent vaccine shows cross-reactivity to other HPV types, in particular to HPV45 and 31, which are phylogenetically similar to HPV18 and 16, respectively [17]. 


\section{Target population}

Genital HPV infection is usually transmitted sexually, and immunisation should therefore precede the start of sexual activity. It implies that the target population for vaccination is prepubertal girls or young adolescents. In addition, the antibody response induced by vaccines is generally higher in prepubertal children [20].

The United States Advisory Committee on Immunization Practices (ACIP) recommends the routine use of the vaccine for 11-12 year-old girls (minimum age nine years) and a catch-up vaccination for women between 13 and 26 years of age, regardless of whether they are sexually active or not [20]. The Canadian National Advisory Committee on Immunization (NACl) advises that girls aged between nine and 13 years should be vaccinated before their sexual debut and that women between 14 and 26 years of age should be vaccinated, regardless of whether they are sexually active or not [21].

The target populations in some European countries are shown in Table 1. In Germany and in the United Kingdom, the HPV vaccine is offered to the target population free of charge. In France, 65\% of the cost is borne by the welfare system and the remaining $35 \%$ are paid by the individual or by a voluntary private insurance [22].

A recent survey on the sexual habits of young Italians indicates that $4 \%$ of girls report to have had their first sexual intercourse at the age of 14 years and $10 \%$ at the age of 15 years. Moreover, the data stratified by age showed that the age of the first sexual intercourse is decreasing within the cohort of 18-29 year-olds (both in men and in women) [23].

Another study compared 16 vaccine strategies in different age cohorts and the corresponding number of infections prevented by HPV. It found that vaccinating 12 year-old girls can be effective in the prevention of HPV infections. Indeed, the majority of 12 year-old girls are not yet sexually active and therefore represent the best target for vaccination [24]. The Superior Council of Health in Italy identified in its opinion on 11 January 2007 pre-adolescence (12 years) as the ideal age for vaccination because of the following considerations:

- Almost none of the children have previously had any sexually transmitted infections;

- The immune response at that age tends to be stronger;

- Children of that age attend the first two classes of secondary school where parents are still much involved and therefore both children and parents can be reached with adequate and relevant information about infection and vaccination;
- There is the possibility to catch up on missed doses of the vaccine in the third class of secondary school;

- Children of that age are under the responsibility of their parents who may insure adherence to the vaccination course;

- The vaccination can be included in the national vaccination schedule [25].

On 22 February 2008, the Italian Minister of Health announced the start of the first public vaccination campaign against HPV for 12 year-old girls [26].

\section{The HPV vaccination campaign in Liguria}

As foreseen in the Regional Decree (DRG) No. 54 on 25 January 2008, the vaccination campaign started on 8 March 2008 and targeted 12 year-old girls (born in 1997) who were offered free vaccination. Moreover, a free not active offer is in place for girls at the age of 13 years (born in 1996), and girls and women between the ages of 14 and 26 years can get the vaccine at a partial price of EUR 105, the cost of the vaccine and its administration incurred for the local public health authority (Azienda Sanitaria Locale, ASL). The objective was to achieve a coverage of $>95 \%$ of the 12 year-old-girls with three doses of vaccine within five years after the start of the vaccination programme [27]. The bivalent vaccine was chosen for the campaign.

The aim of this work was to assess the adherence to HPV vaccination in 12 and 13 year-old girls during the vaccination campaign in the ASL 5 "Spezzino", from March to December 2008. The study analysed all girls (12-13 years-old-girls) vaccinated as part of the active free offer as well as the not active free offer, and also noted the adherence to vaccination in people who paid the partial costs for their vaccination.

\section{Materials and methods}

This study shows the results of the HPV vaccination in the province of La Spezia in the region of Liguria. This province is served by the ASL 5 "Spezzino". The resident population of La Spezia on 31 December 2007 was 218,032 people [28]. Healthcare is provided by four hospitals and three social health districts.

The recruitment of birth cohorts 1996 and 1997 for vaccination was made using the municipal registers. The other birth cohorts were not recruited, but signed up for the vaccination themselves. An invitation letter was sent to the girls' parents to explain the campaign. It included a regional information brochure, the informed consent form, and the date on which to present to the outpatient clinics for vaccination. A second invitation letter was sent if parents did not respond. Moreover, if girls stopped the vaccination cycle after the first or second dose of vaccine, a reminder letter was sent, containing a consent or dissent form to be completed and returned.

T A B L E 1

Details of HPV vaccination programmes introduced in some European countries as of $310 \mathrm{October} 2007^{\star}$

\begin{tabular}{|l|c|c|c|c|}
\hline Characteristics & Austria & France & Germany \\
\hline Target population & Girls and boys before sexual debut & 14 year-old girls & $12-17$ year old girls & $12-13$ year-old girls \\
\hline Catch-up & No & $\begin{array}{c}15-23 \text { year-old women, sexually active } \\
\text { or who started sexual activity in the } 12 \\
\text { previous months }\end{array}$ & $\begin{array}{c}16-18 \text { year-old women from autumn } \\
2009 \text { and 15-17 year-old women from } \\
\text { autumn 2010 }\end{array}$ & \begin{tabular}{c} 
No \\
\hline
\end{tabular} \\
\hline
\end{tabular}


A similar invitation letter was sent to the 1996 birth cohort together with the regional information brochure and a phone number to call for an appointment.

Information campaigns on prevention interventions and health promotion targeting adolescents are often fragmented and without continuity. They often do not integrate the work of health and education services and voluntary associations. Therefore, the ASL 5 coordinated the activities for the HPV vaccination campaign, involving different areas of expertise such as general practitioners, paediatricians, local nursery and infant health services, school authorities, local press and families.

The general practitioners, paediatricians, and local nursery and infant health services received posters to be displayed in their

\section{F I G U R E}

HPV vaccine doses administered from March to December 2008 to girls born in 1997 and 1996, by month, in La Spezia province

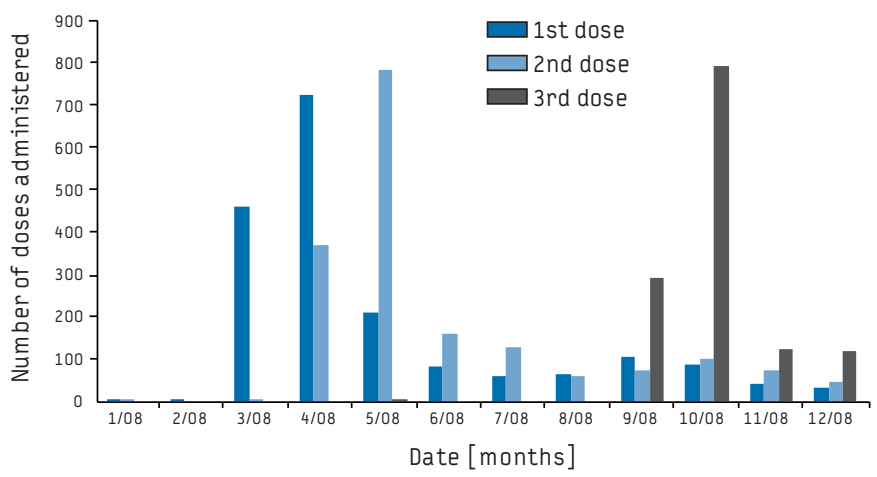

waiting rooms, containing the email addresses and internet links of where to obtain information about the vaccination. They also actively informed parents and girls about transmission, consequences of HPV infection and the protection the new vaccine could offer. ASL staff also prepared and distributed brochures in all schools in the province of La Spezia. In a simple and understandable way, the girls were informed about the benefits of vaccination and invited to ask their paediatricians for further information.

Gynaecologists and local public health experts held a press conference explaining in detail how the immunisation campaign was organised and the benefits it offered. Local newspapers reported on the beginning of the immunisation campaign, with an invitation to call the vaccination clinics for any information about it. Finally, the ASL 5 website posted a link to the HPV vaccination campaign site containing frequently asked questions about vaccination (prepared by the National Screening Observatory) and the procedures for access to the public health clinics throughout the territory.

Vaccination teams were established to reduce outpatient waiting times. These vaccination units consisted of a physician, a nurse and an administrative technician. In addition, compensation was provided for staff working outside normal office hours to enable vaccination sessions in the afternoon. Data were collected from March to December 2008 in a computerised vaccination registry. The percentage of adherence to the vaccination was calculated as the number of doses administered per target resident population $x$ 100. Adverse reactions to the vaccine were reported to the regional Department of Health, following the established routine for adverse reactions to other vaccines.

Results

The figure shows the number of doses administered between March and December 2008. The majority of first doses were

HPV: human papillomavirus.

T A B L E 2

Number of HPV-vaccinated girls per birth cohort (1997-1982) and relative vaccination adherence, Italy, March to December 2008

\begin{tabular}{|c|c|c|c|c|}
\hline Birth cohorts & Resident girls (no.) & Vaccinated girls first dose (\%) & Vaccinated girls second dose (\%) & Vaccinated girls third dose (\%) \\
\hline 1997 & 825 & 80.6 & 79.0 & 64.1 \\
\hline 1996 & 854 & 74.5 & 73.5 & 58.1 \\
\hline 1995 & 782 & 12.3 & 11.9 & 7.2 \\
\hline 1994 & 761 & 10.1 & 9.9 & 5.4 \\
\hline 1993 & 753 & 10.1 & 11.7 & 5.8 \\
\hline 1992 & 841 & 12.5 & 7.5 & 6.3 \\
\hline 1991 & 782 & 8.2 & 6.2 & 3.6 \\
\hline 1990 & 836 & 6.7 & 2.1 & 5.0 \\
\hline 1989 & 844 & 2.3 & 2.0 & 1.3 \\
\hline 1988 & 842 & 2.5 & 1.6 & 1.2 \\
\hline 1987 & 797 & 1.9 & 1.4 & 0.9 \\
\hline 1986 & 846 & 1.7 & 1.2 & 0.7 \\
\hline 1985 & 852 & 1.8 & 1.2 & 0.8 \\
\hline 1984 & 902 & 1.4 & 1.3 & 0.6 \\
\hline 1983 & 862 & 1.3 & 0.6 & 0.8 \\
\hline 1982 & 978 & 0.9 & 4.6 & 0.4 \\
\hline total $1982-1995$ & 11,678 & 5.0 & & \\
\hline
\end{tabular}

HPV: human papillomavirus 
administered by the vaccination clinics during the months of March and April, following the administration of the first dose on 19 March, with a slight increase in September, which, according to statements from girls and parents, may be related to the Nobel Prize in Medicine awarded to Harald zur Hausen who is dedicated to the study of HPV.

The percentage of adherence to the vaccination was $80.6 \%$, $79.0 \%$ and $64.1 \%$, respectively, for the first, second and third dose in the 1997 birth cohort, and $74.5 \%, 73.5 \%$ and $58.1 \%$ in the 1996 birth cohort. As expected, the adherence in older age groups was lower: $5.0 \%, 4.6 \%$ and $2.7 \%$, respectively, in those born between 1995 and 1982 . Table 2 shows the number of vaccinated girls born between 1982 and 1997 and the relative vaccination adherence.

As of 31 December 2008, only three girls born in 1997 had stopped taking the vaccine after the first dose. Twenty girls had stopped after taking the second dose. In the 1996 birth cohort were two girls hat stopped after the first dose, one of them due to an adverse reaction, and 22 had interrupted the vaccination after the second dose (one due to an adverse reaction).

In the assessment of side effects due to the vaccine (data not shown) that occurred within seven days after administration, local effects were the most frequent, especially pain and redness in the inoculation site. The most frequently observed systemic side effects were fatigue, general malaise and gastrointestinal symptoms, which is in agreement with the literature [15-17].

Two adverse reactions involved girls born in 1996. One was characterised by redness and induration at the breast ipsilateral to the inoculated arm. It appeared about 12 hours after the first vaccination and resolved spontaneously within a few days. This reaction led to the decision to suspend the vaccination cycle. The other one, following administration of the second dose of vaccine, was characterised by a severe form of atopy which resolved spontaneously in a girl with a history of atopic dermatitis. This girl had already presented erythema and itching with lower intensity after the first dose of vaccine. Again, as a precaution, it was decided to suspend the vaccination course.

\section{Discussion and conclusion}

HPV vaccination is a new important instrument to prevent the occurrence of a specific cancer. The success of a vaccination campaign depends on several factors including support from policy makers, the presence of qualified and expert health professionals and the cost-effectiveness of the vaccine. It is necessary to provide the population with clear, concise and simple information about HPV infections, cervical cancer, prevention and vaccination. It is important that healthcare workers are well trained in communicating with patients to insure professional credibility and aid the promotion and implementation of coordinated vaccination campaigns.

There are as yet no published national or international data on how many vaccine doses were administered in countries that have already run HPV vaccination campaigns, and how many people were vaccinated or completed the vaccine course. It is estimated that the target population, 12 year-old girls, was about 280,000 in Italy [26] and 6,000 in the region of Liguria [27]. Considering the expected objective for Liguria to achieve a coverage of $>95 \%$ of the 12 year-old girls with three doses of vaccine within five years after the start of the vaccination programme [27] and the Ligurian pooled data which show an adherence to HPV vaccination of about
$62 \%$ among 12 year-old girls [29], the results obtained during the HPV vaccination campaign in 2008 in the ASL 5 "Spezzino" $(80 \%$ adherence) are to be considered very good.

Adverse reactions to all vaccines have to be reported to the regional Department of Health to ensure post-licensure monitoring of the safety of the vaccine. In the 2008 HPV vaccination campaign the ASL 5 "Spezzino" observed only two moderate adverse reactions that did not require hospitalisation or medication and resolved spontaneously. With regard to the tolerability of the vaccine, these side effects were comparable to those observed in the literature [15-17] and the number of girls who interrupted their vaccination course was limited (two girls).

The involvement of girls and their parents in the vaccination campaign was very high and they showed a considerable interest in HPV and the consequences that the infection may have. General practitioners and paediatricians received many requests for information from parents of girls involved in the campaign and their number of patients increased. In the first month of the campaign the website was accessed more than 500 times and 300 phone calls were made to the dedicated numbers. The main points of our programme were the implementation of educational campaigns targeted according to age and sex, the involvement of educational institutions, information about the transmission of the infection and an increase in staff at vaccination clinics during the campaign.

In conclusion, we can say that the information campaign carried out throughout the province was conducted successfully and appropriately. However, this is only a starting point. To further raise the awareness of girls and parents regarding HPV vaccination, the quality of the information and especially the quality of healthcare and vaccination services needs to be improved.

\section{References}

1. Trottier H, Franco EL. The epidemiology of genital human papillomavirus infection. Vaccine. 2006;24 Suppl 1: S1-15.

2. World Health Organization. Report of the Consultation on Human Papillomavirus Vaccines. Geneva: WHO; 2005. Available from: http://whqlibdoc.who.int/hq/2005/ WHO_IVB_05.16.pdf

3. World Health Organization (WHO) and Institut Català d'Oncologia (ICO) Information Centre on Human Papilloma Virus and Cervical Cancer. HPV and cervical cancer in the world 2007 report. Vaccine. 2007;25 Suppl 3:C1-230.

4. Clifford GM, Franceschi S, Diaz M, Nubia Munoz N, Villa L. HPV type-distribution in women with and without cervical neoplastic diseases. Vaccine. 2006;24 Suppl 3:S3/26-34

5. Castle PE, Schiffman M, Herrero R, Hildesheim A, Rodriguez AC, Bratti MC, et al. A prospective study of age trends in cervical human papillomavirus acquisition and persistence in Guanacaste, Costa Rica. J Infect Dis. 2005;191(11):1808-16.

6. Bosch FX, Manos MM, Munoz N, Sherman M, Jansen AM, Peto J, et al. Prevalence of human papillomavirus in cervical cancer: a worldwide perspective. International biological study on cervical cancer (IBSCC) Study Group. J Natl Cancer Inst. 1995;87(11):796-802.

7. Munoz N, Bosch FX, de Sanjose S, Herrero R, Castellsagué X, Shah KV, et al Epidemiologic classification of human papillomavirus types associated with cervical cancer. N Engl J Med. 2003;348(6):518-27.

8. Clifford GM, Smith JS, Plummer M, Franceschi S. Human papillomavirus types in invasive cervical cancer worldwide: a meta-analysis. $\mathrm{Br} \mathrm{J}$ Cancer 2003;88(1):63-73.

9. Cuschieri KS, Cubie HA, Whitley MW, Seagar AL, Arends MJ, Moore C, et al. Multiple high risk HPV infections are common in cervical neoplasia and young women in a cervical screening population. J Clin Pathol. 2004;57(1):68-72.

10. Stanley M, Lowy DR, Frazer I. Prophylactic HPV vaccines: Underlying mechanisms. Vaccine. 2006;24 Suppl 3:S3/106-13.

11. Dillner J. The serological response to papillomaviruses. Semin Cancer Biol. $1999 ; 9(6): 423-30$ 
12. Frazer IH, Cox JT, Mayeaux EJ Jr, Franco EL, Moscicki AB, Palefsky JM, et al. Advances in prevention of cervical cancer and other human papillomavirus related diseases. Pediatr Infect Dis J. 2006;25(2 Suppl):S65-S81, quiz S82.

13. Inglis S, Shaw A, Koenig S. HPV vaccines: commercial research \& development. Vaccine. 2006+24 Suppl 3S3/99-S!05.

14. United States Food and Drug Administration (U.S. FDA). Vaccines and Related Biological Products Advisory Committee Meeting; May 18, 2006. [Accessed 26 April 2009].

15. Harper DM, Franco EL, Wheeler C, Ferris DG, Jenkins D, Schuind A, et al Efficacy of a bivalent L1 rirus-like particle vaccine in prevention of ilfectioj with human papillomavirus 4ypes 16 and 18 in young women: a rafdomised controlled trial. Lancet. 2004;364(9447):1757-65.

16. Villa LL, Costa RL, Petta CA, Andrade RP, Ault KA, Giuliano AR, et al. Prophylactic quadrivalent human papillomavirus (types $6,11,16$, and 18) L1 virus-like particle vaccine in young women: a randomised double-blind placebocontrolled multicentre phase II efficacy trial. Lancet Oncol. 2005;6(5):271-8.

17. Harper DM, Franco EL, Wheeler CM, Moscicki AB, Romanowski B, Roteli-Martins CM, et al. Sustained efficacy up to 4.5 years of a bivalent L1 virus-like particle vaccine against human papillomavirus types 16 and 18: follow-up from a randomised control trial. Lancet. 2006;367(9518):1247-55.

18. Villa LL, Ault KA, Giuliano AR, Costa RL, Petta CA, Andrade RP, et al. Immunologic responses following administration of a vaccine targeting human papillomavirus types 6, 11, 16 and 18. Vaccine. 2006;24(27-28):5571-83.

19. Poland GA, Jacobson RM, Koutsky L@, T`mms GM, Raalkar R, Smith JF, et al. Immunogenicity and reactogenicity of a novel vaccine for human papillomavirus 16: a 2-year randomized controlled clinical trial. Mayo Clin Proc. 2005;80(5):601-10.

20. Markowitz LE, Dunne EF, Saraiya M, Lawson HW, Chesson H, Unger ER; Centers for Disease Control and Prevention (CDC); Advisory Committee on Immunization Practices (ACIP). Quadrivalent human papillomavirus vaccine. Recommendations of the Advisory Committee on Immunization Practices (ACIP). MMWR Recomm Rep. 2007;56(RR2):1-24.

21. Shefer A, Markowitz L, Deeks S, Tam T, Irwin K, Garland SM, et al. Early Experience with Human Papillomavirus Vaccine Introduction in the United States, Canada and Australia. Vaccine. 2008;26 Suppl 10:K68-75.

22. King LA, Lévy-Bruhl D, O’Flanagan D, Bacci S, Lopalco PL, Kudjawu Y, et al. VENICE country specific gate keepers and contact points. Introduction of human papillomavirus (hpv) vaccination into national immunisation schedules in Europe: results of the VENICE 2007 survey, Euro Surveill 2008; 13(33):pii:18954. Available from: www.eurosurveillance.org/ViewArticle.aspx?ArticleId=18954

23. Signorelli C, Colzani E. Age at first intercourse and HPV immunization. J Prev Med Hyg. 2007;48(2):37-8.

24. Gasparini R, Amicizia D, Manfredi P, Ansaldi F, Lucioni C, Gallelli G, et al. Human papillomavirus vaccination: what is the best choice? A comparison of 16 strategies by means of a decisional model. Epidemiol Infect. 2009;137(6):794802. [Epub 2008 0ct 17].

25. Ministero della Salute, Consiglio Superiore della Sanità. Sessione XLVI, sessioni congiunte II e III. Seduta dell'11 gennaio 2007. Strategie per l'offerta attiva del vaccino contro l'ifezione da HPV in Italia. [Ministry of Health. Meeting minutes from joint sessions II and III on "Strategies for an active offer of vaccine against HPV infections in Italy]. [Italian]. Available from: http://www.ministerodellasalute.it/imgs/C_17_pubblicazioni_600_allegato. pdf

26. Ministerio della Salute. Intervento del Ministro della Salute. Conferenza stampa: presentazione campagna vaccinale contro l'HPV. 22 febbraio 2008. [Ministry of Health. Intervention by the Italian Minister for Health]. [Italian]. Available from: http://www.ministerosalute.it/speciali/documenti/ vaccinazioni/HPV_discorso_del_Ministro_22_febbraio_2008.pdf

27. Regional Concil. Campagna vaccinale contro HPV (Human Papilloma Virus). [Vaccine campaign against HPV]. D.G.R. Liguria n. 54 del 25 gennaio 2008 della Regione Liguria. [Italian].

28. Demo.ISTAT.it [homepage on the Internet]. Rome: The National Institute of Statistics. Demographic indicators. Available from: http://demo.istat.it/ pop2008/index.html

29. Carloni R. Campagna vaccinale per HPV. L'esperienza della Regione Liguria ad un anno dall'avvio. Donne e HIV/HPV. [Vaccine campaign for HPV. The experience of the Region Liguria one year after. Women and HIV/HPV]. Genoa, 5 March 2009. 